УДК 323.25

СОКОЛОВ Александр Владимирович - кандидат политических наук, доцент кафедры социальнополитических теорий Ярославского государственного университета им. П.Г. Демидова (150003, Россия, г. Ярославль, ул. Советская, 10; alex8119@таil.ru)

КУРБАНОВА Асият Ахмедовна - магистрант Санкт-Петербургского государственного университета (199034, Россия, г. Санкт-Петербург, Университетская наб., 7-9; kurbanovaаsyat@таil.ru)

\title{
ИНТЕРНЕТ-ТЕХНОЛОГИИ В МАССОВЫХ ДВИЖЕНИЯХ
}

Аннотация. Современные политические процессы характеризуются все большей вовлеченностью масс. Граждане, организуясь в массовые движения, стремятся оказать воздействие на процесс принятия решений органами власти и защитить свои интересы. Будучи разрозненными и не обладая необходимыми ресурсами, они демонстрируют низкую эффективность своих действий. Развитие Интернета существенно упростило самоорганизацию граждан, облегчив коммуникацию, координацию действий, процесс распространения информации. Данные преимущества Интернета существенно упростили процесс мобилизации граждан в массовые движения, позволили повысить эффективность действий массовых движений. Социальные сети, различные интернет-платформы стали ключевыми инструментами в организации массовых движений.

Ключевые слова: протест, Интернет, массовые движения, сетевое взаимодействие, мобилизация, коммуникация

$\mathrm{M}$ ассовые движения в условиях глобализации приобретают новые черты и свойства. Так, Т.П. Малькова подчеркивает, что в современном мире глобализация ведет к необходимости рассматривать проблему управления массами, массовым сознанием в более широком контексте. Она считает, что информационные технологии дают возможность мгновенно рассматривать социально значимую информацию, а Интернет дает человеку возможность высказать свою точку зрения и близким по духу людям объединиться в группу [Малькова 2012].

Стоит отметить, что массовые движения формируются и расширяются за счет коммуникационных связей, которыми обладают их участники. Масса образуется чаще всего из обычных граждан. При этом степень влиятельности массовых движений зависит от числа участников, поддерживающих данное движение (качество этих общностей).

Одними из самых сильных средств воздействия на массовое сознание являются средства массовой информации и Интернет. Интернет выполняет важную роль в формировании структуры и содержания современного массового сознания.

По мнению М.И. Найдорфа, «массовые движения возникают при определенных социальных обстоятельствах, которые воспринимаются гражданами чаще всего как нетерпимые» [Найдорф 2010]. Граждане могут участвовать в политической жизни страны, формируя временные образования, такие как митинги, демонстрации. В качестве основных черт поведения человека, участвующего в массовом движении, можно отметить высокий уровень эмоций, снижение уровня интеллекта и разума, отсутствие личной ответственности. Для поведения масс характерна стихийность, массы никогда не рефлексируют, не осмысливают свои действия.

Развитие информационных технологий (Интернет, социальные сети) способствовало конструированию сетей между участниками движения. С одной стороны, все участники массовых движений являются свободными в своих действиях и имеют возможность выражать свою точку зрения, но эти действия имеют силу только в рамках общности, коллектива. 
Общественные движения являются «практиками, упорядоченными в пространстве и времени», которые организуются акторами и регулярно воспроизводятся [Якушина 2014]. При взаимодействии каждый индивид использует определенные ресурсы и руководствуется нормами и правилами. В связи с этим теория структурации определяет общественные движения как системы, в которых воспроизводятся отношения между акторами и коллективами [Сколебина 2010].

Движения - это определенные организованные практики, которые для своего дальнейшего функционирования нуждаются в индивидах, наделенных определенными качествами [Якушина 2014]. Участники массового движения являются активными индивидами, которые принимают решения осознанно.

Феномен массовых движений становится важной частью общественнополитической жизни России. Ю.А. Зуляр акцентирует внимание на том, что «массовые движения привлекают в свои ряды многочисленных сторонников тем, что не придерживаются в своей деятельности строгой идеологической концепции» [Зуляр 2008]. Для того чтобы движение стало массовым, необходимо достичь такого состояния беспокойства широкой массы людей по поводу проблемы, затрагивающей их жизненные потребности, чтобы возникли значительные мотивы, побуждающие граждан участвовать в таком виде движения.

Формирование и развитие движений зависит от организационных ресурсов, от уровня развитости институтов гражданского общества. Массовые движения возникают в определенной институциональной среде, которая оказывает влияние на участников и их поведение. При возникновении изменений в сфере жизни общества массовые движения выступают как носители новых идей.

Массовые движения играют важную роль в общественной жизни при наличии устойчивой структуры, действующей в течение определенного времени. В России 1990-е гг. задача массовых движений состояла в координации действий по объединению демократических сил общества для проведения социальноэкономических реформ в России [Монусова 1993]. Исследования последних лет свидетельствуют, что после беспрецедентного всплеска активности масс конца 1980-х - начала 1990-х гг. общество перешло в стадию своеобразной «глухой самообороны», сопровождающейся снижением уровня политической активности россиян. По мнению В.В. Петухова, выросло целое поколение людей, которые уже ничего не ждут от власти, от общественных институтов и действуют в «автономном режиме» [Петухов 2006: 23]. По результатам проведенного исследования Н.Н. Седова подчеркивает, что участие в общественно-политических акциях (митингах, демонстрациях и т.п.) практикуют сегодня $3 \%$ россиян. При этом данная форма гражданского активизма не предполагает постоянное, регулярное, системное участие [Седова 2014].

Во многом поэтому различные гражданские инициативы и массовые протестные движения расцениваются как малозначимые. Основные причины снижения роли движений - их организационная слабость, неустойчивость, ограниченность численности участников и большей степени - их неуспешность в достижении своих целей и интересов.

Как во всех странах мира, в России основой возникновения новых массовых движений является недовольство существующей социально-политической ситуацией в стране (движения обманутых дольщиков, защитников окружающей среды, автомобилистов и т.д.). При этом проблема, которая побуждает граждан к активным протестным действиям, должна быть конкретной и острой, касающейся обыденной жизни, базовых потребностей (пример, угроза выселения человека из его жилья). 
Новые социальные движения возникают в наиболее массовых слоях населения, среди граждан, «чьи доходы позволяют им сводить концы с концами до тех пор, пока в их ситуации не случаются существенные перемены (внезапное лишение социальных гарантий, риск потерять свое жилье). Эти люди, повседневно встречающиеся с социально-политическими проблемами и рисками, составляют большинство (массу) населения, по меньшей мере, в больших и средних городах» [Ворожейкина 2008: 20]. Без их заинтересованного участия никакие демократические институты в России не будут устойчивыми.

Стоит отметить, что различные формы протестной активности показывают существующие потребности, интересы граждан; с помощью протестов можно выявить актуальные проблемы и причины недовольства граждан. Примером могут служить акции, посвященные расследованию Фонда борьбы с коррупцией, проведенные в более чем 80 российских городах 26 марта и 12 июня 2017 г. Большинство протестных акций не были согласованы с властями. Согласно оценке Фонда общественного мнения, причиной для протестных акций послужило недовольство властями, снижение уровня жизни граждан и протест против коррупции 1 .

Жилищный вопрос является одним из часто поднимаемых в массовых протестных движениях. Программа реновации в Москве создала новые факторы формирования протестных настроений и самоорганизации граждан. В частности, в Москве на Суворовской площади 27 мая 2017 г. прошла массовая акция протеста «За права москвичей» против реновации пятиэтажек.

В то же время нельзя говорить о том, что массовые движения не влияют на политический процесс и принятие решений. Активное освещение проводимых акций и митингов в СМИ, различные публикации и исследования отражают актуальность массовых движений. При возникновении различных акций протеста власть должна выстраивать диалог с инициативными группами, гражданским обществом с целью решения возникающих проблем.

Развитие интернет-технологий оказывает значительное влияние на процесс коммуникации, формирование и развитие массовых движений. По мнению О.Н. Яницкого, Интернет и информационные технологии стали главным инструментом мобилизации ресурсов. Политическая мобилизация представляет коллективное действие, цель которого - изменение сложившейся социально-политической ситуации путем публичного выражения несогласия. Сегодня наличие разнообразных видов общения между людьми являются основополагающим «средством коммуникации и самоорганизации, как протестной, так и созидательной, конструктивной» [Яницкий 2012: 3].

Согласно данным исследовательской компании GfK Group, в России с 2017 г. аудитория интернет-пользователей от 16 лет и старше увеличилась на 3 млн чел. и на данный момент составляет 87 млн жителей страны. При этом наиболее активными пользователями Интернета в России являются молодые люди в возрасте 16-29 лет ${ }^{2}$.

Развитие интернет-пространства расширило коммуникационные возможности граждан, при этом интернет-технологии выступают сильным механизмом воздействия на массовое сознание. Так, Ю.А. Ильичева подчеркивает, что рост интереса к мобилизационным технологиям возник с появлением нового информационного пространства [Ильичева 2013].

\footnotetext{
1 Фонд общественного мнения. Акции протеста 12 июня: опросы накануне и после протестов. Доступ: http://fom.ru/Nastroeniya/13591

2 Исследование GfK: Проникновение Интернета в Россию. Доступ: http://gtmarket.ru/organizations/ gfk/gfk-info (проверено 07.09.2018).
} 
Использование интернет-технологий является главной особенностью современной политической коммуникации в России. Растет число граждан, которые используют Интернет не только для получения информации, но и для обмена мнениями по политическим вопросам. Интернет-коммуникация способствует преодолению отчуждения и формирует новые каналы участия граждан в политике. Благодаря расширению информационного пространства в политике, граждане могут ощущать свою причастность к политическому процессу и возможность влиять на принятие решений. Активное развитие информационных технологий и платформ способствует повышению интенсивности обсуждения важных вопросов, затрагивающих интересы общества. Интернет включает неограниченный массив информации, а сегодня также наблюдается рост общественных обсуждений, которые способствуют активизации населения и его мобилизации на участие в политической жизни страны [Авзалова 2015]. Интернет оказывает влияние на общественную сферу, что содействует как расширению спектра обсуждаемых идей и предложений, так и активному вовлечению граждан. Интернет способствует эффективному формированию политического дискурса, т.к. создаются новые способы донесения информации до граждан и организации граждан для участия в разных видах политических мероприятий и акций. В целом Интернет представляет собой коммуникационную сеть, для которой характерны такие свойства, как интерактивность, открытость, равенство.

Сформированные интернет-платформы представляют непосредственную форму взаимодействия, которая способствует привлечению активных участников и формирует общение между гражданами. Стоит обратить внимание на то, что онлайн-сообщества оказывают содействие в создании идентичности в онлайн-среде, при этом формирование идентичности является главной функцией виртуальной публичной сферы. Следовательно, коллективная идентичность формируется при условии включения в онлайн-коммуникацию значительного числа граждан.

Результат массовых движений во многом зависит от эффективности воздействия информационных технологий, как индивидуальных, так и коллективных. Тем не менее Интернет может оказывать влияние на мотивы, лежащие в основе коллективных действий, и тем самым воздействовать на характер массовых движений.

Различные формы информационно-коммуникационных технологий стали для российских граждан инструментом самоорганизации. С помощью правильно выстроенной коммуникации можно оказывать влияние на субъект, а виртуальное общение также способствует изменению участвующего в ней субъекта. Следует выделить следующие черты интернет-коммуникации: анонимность общения, на которое не влияет ни возраст, ни социальный статус человека, отсутствие реальной связи между людьми. А.А. Никифоров, рассматривая влияние новых медиа на массовую коммуникацию, подчеркивает, что социальные сети изменяют способы коммуникации, т.к. возрастает возможность межличностного общения на основе публикуемых в сети сообщений [Никифоров 2014: 1904].

А.С. Шерстобитов указывает, что Интернет является площадкой, с помощью которой происходит социализация пользователей. С развитием информационно-коммуникационных технологий политические лидеры стали активнее использовать Интернет для политической мобилизации населения [Шерстобитов 2013]. Рост популярности социальных сетей трансформирует взаимодействие людей, т.к. здесь «преобладает обезличенный характер коммуникации», которая заменяет живое общение через употребление таких инструментов общения, как мемы, лайки, репосты, комментарии. 
С точки зрения Д.С. Голосманова, социальные сети создают новые информационные ресурсы, которые предоставляют человеку «возможность участвовать в процессе создания, хранения и распространения социально значимой информации» [Голосманов 2012]. Специфика видеоблогов, постов в социальных сетях заключается в том, что они могут создаваться и распространятся самими пользователями.

Внедрение интернет-технологий преобразовывает массовую коммуникацию, включая и новые формы общения и гражданского участия. Однако эти технологии оказывают глубокое влияние на ценности и политические установки граждан. Социальные сети служат платформой, где каждый человек может получить доступ к различным информационным источникам, а также Интернет может предоставлять виртуальное пространство для выражения интересов граждан. Социальные сети с точки зрения онлайн-мобилизации важны для обмена информацией и предоставления каналов для коммуникации сторонников с организаторами.

Рассматривая информационные технологии, стоит обратить внимание на их взаимосвязь с социальными движениями в трех основных направлениях: это 1) обмен информацией; 2) выражение политических взглядов; 3) мобилизация.

Использование интернет-технологий оказывает влияние на общественные движения. В целом общественные движения представляют собой самоорганизующиеся сети, основывающиеся на разделяемых ценностях и взглядах, которые мобилизуются в результате возникновения конкретных проблем и используют различные виды акций. Стоит отметить, что в социальных взаимосвязях преобладает добровольная форма участия, которая объединяет граждан для решения существующих проблем [Сколебина 2010]. Из данного определения следует, что коллективные действия отражают ценности, сформировавшиеся в обществе, а также направления социально-политических изменений. Социолог П. Штомпка рассматривает социальные движения как наиболее сложную форму проявления коллективной активности. Основная цель любых видов социальных движений - осуществление социальных изменений. Также движения развиваются в рамках неформальных систем, не носят институциональный и формализованный характер [Штомпка 2005].

В основе концепции новых общественных движений лежит идея саморегуляции и самоорганизации небольших неформализованных групп, для которых не характерно жесткое централизованное управление. О.А. Усачева акцентирует внимание на том, что новые общественные движения «используют возможности информационно-коммуникационных технологий, так как соответствуют организационным требованиям» [Усачева 2012]. Соответственно, информационно-коммуникационные технологии выступают главным инструментом мобилизации и влияют на эффективность координации деятельности общественных движений.

Рассматривая роль информационных технологий в политике, Э.И. Авзалова утверждает, что «интернет-коммуникация способствует преодолению отчуждения» и формирует новые каналы участия граждан в политике [Авзалова 2015].

Коллективная идентичность, формируемая через Интернет, создает новые социальные процессы, сообщества, которые основаны на общих интересах. Интернет предоставляет новые способы самовыражения и участия при помощи социальных сетей - начиная с анонимных электронных журналов до личных видеоблогов. Кроме того, Интернет - эффективное инновационное общественное пространство, которое способствует развитию социальных объедине- 
ний и движений. Действительно, Интернет расширяет доступ пользователей к интересующей информации, материалам и предлагает новые возможности для политической коммуникации [Филатова 2014: 58].

В настоящее время Интернет активно преобразует коллективные действия. Это не просто социальное пространство, а площадка для общения, создания сообществ и движений и обсуждения важных проблем, волнующих общество. Граждане используют платформы, в которых они могут выражать требования к существующим структурам власти. Необходимо отметить и высокую скорость распространения, получения информации и обмена ею в социальных сетях, что способствует мобилизации граждан на участие в акциях. Интернет-платформы и социальные сети позволяют координировать коллективные действия в определенных формах акций, поэтому они стали площадкой для политической коммуникации и организации масс. Так, О.Е. Гудошникова утверждает, что сегодня Интернет представляет собой инструмент, который улучшает политическую коммуникацию и содействует привлечению социально-политически активных граждан [Гудошникова 2015].

Таким образом, массовые движения представляют собой единство граждан, которые стремятся добиться определенной цели, связанной с выражением коллективного недовольства или, напротив, поддержкой возникших социальных изменениий в обществе. Ключевым инструментом мобилизации граждан в массовые движения становится Интернет. Рост популярности социальных платформ создает новые цифровые социальные сети, в которых граждане могут взаимодействовать и быстро делиться информацией, мнениями. Социальные сети обеспечивают коммуникацию на расстоянии.

Социальные сети обладают коллективными инструментами, которые направлены на рост участия граждан в социально-политической жизни, быстрое распространение информации; они также эффективны для организации и выстраивания доверия в массах.

В связи с этим главная особенность современной политической интернеткоммуникации в общественных движениях - это использование социальных сетей и платформ. Возрастает число граждан, которые используют Интернет не только для получения информации, но также для обмена мнениями по социально-политическим вопросам. Интернет-технологии и социальные сети позволяют координировать коллективные действия в определенных формах акций, а также они стали площадкой для политической коммуникации и организации массовых движений.

Исследование выполнено при финансовой поддержке РФФИ в рамках научно-исследовательского проекта № 17-33-01022 (а2) "Моделирование и индексирование протестной активности в субъектах Российской Федерации».

\section{Список литературы}

Авзалова Э.И. 2015. Методологические особенности изучения роли интернет-коммуникации в политике. - Известия Саратовского университета. Новая серия. Сер. Социология. Политология. Т. 15. № 2. С. 113-117.

Ворожейкина T.Е. 2008. Самозащита как первый шаг к солидарности. - Pro et Contra. № 2-3. C. 6-23.

Голосманов Д.С. 2012. Интернет как среда политической коммуникации: перспективы и противоречия. - Вестник Сибирского государственного индустриального университета. № 2. С. 66-69. 
Гудошникова О.Е. 2015. Технологии «новых медиа» как платформа гражданской активности. - Современные проблемы науки и образования. № 1-1.

Зуляр Ю.А. 2008. Политология: Базовый курс: учебное пособие. В 2 т. Иркутск: ГУ НЦ РВХ ВСНЦ СО РАМН. Т. 1. 592 с.

Ильичева Ю.А. 2013. Мобилизационные технологии: сущность, предпосылки возникновения, основные инструменты и средства. - Медиаскоп. № 2.

Малькова Т.П. 2012. Массовое сознание как социокультурный феномен: тенденции развития. - Новое в психолого-педагогических исследованиях. № 2. С. 38-46.

Монусова Г.А. 1993. Мотивы и ценности участия в демократическом движении. - Социс. Социологические исследования. № 6. С. 66-70.

Найдорф М.И. 2010. Массовые движения в массовых обществах. - Вестник Русской христианской гуманитарной академии. № 4. С. 220-230.

Никифоров А.А. 2014. Возможности и ограничения протестной мобилизации через социальные сети. - Право и политика. № 12. С. 1903-1909.

Петухов В.В. 2006. Гражданское общество и демократия участия. - ВЦИОМ. Мониторинг общественного мнения. № 1(77). С. 23-26.

Седова Н.Н. 2014. Гражданский активизм в современной России: форматы, факторы, социальная база. - Социологический журнал. № 2. С. 48-71.

Сколебина Н.А. 2010. Общественные движения как объект социологического исследования. - Вестник Волгоградского государственного университета. Сер. 7. Философия. Социология и социальные технологии. № 1(11). С. 51-57.

Усачева О.А. 2012. Сети гражданской мобилизации. - Общественные науки и современность. № 6. С. 35-42.

Филатова О.Г. 2014. Интернет-технологии политической мобилизации в современной России. - Политическая экспертиза: ПОЛИТЭКС. Т. 10. № 4. С. 57-67.

Шерстобитов А.С. 2013. «Сетевая публичность» как новый фактор политической мобилизации в современной России: попытка сетевого анализа. - Вестник Санкт-Петербургского университета. Сер. 6. Философия. Культурология. Политология. Право. Международные отношения. № 3. С. 99-105.

Штомпка П. 2005. Социология. Анализ современного общества. М.: Логос. 664 с.

Якушина О.И. 2014. Идентичность в социологической теории. - Современные проблемы науки и образования. № 4. С. 87-95.

Яницкий О.Н. 2012. Массовая мобилизация: проблемы теории. - Социс. Социологические исследования. № 6. С. 3-12.

SOKOLOV Aleksandr Vladimirovich, Cand.Sci. (Pol.Sci.), Associate Professor of the Chair of Socio-Political Theories, Yaroslavl Demidov State University (10 Sovetskaya St, Yaroslavl, Russia, 150003; alex8119@mail.ru)

KURBANOVA Asyat Akhmedovna, Master student of Saint-Petersburg State University (7-9 Universitetskaya Emb, Saint-Petersburg, Russia, 199034; kurbanovaasyat@mail.ru)

\title{
INTERNET TECHNOLOGIES IN MASS MOVEMENTS
}

\begin{abstract}
Modern political processes are characterized by an increasing involvement of masses. Citizens, organizing themselves in mass movements, seek to influence the decision-making process by the authorities and protect their interests. Being fragmented and lacking the necessary resources, they demonstrate low effectiveness of their actions. The development of the Internet has greatly simplified the self-organization of citizens by facilitating communication, coordination of actions and the process of disseminating information. These advantages of the Internet have significantly simplified the process of mobilizing citizens into mass movements and have made it possible to increase the effectiveness of the actions of mass movements. Social networks, various Internet platforms have become key tools in organizing mass movements.
\end{abstract}

Keywords: protest, Internet, network cooperation, mass movement, mobilization, communication 